\title{
Fantasmas e delírios de ânimos tristes e amedrontados: insegurança e gênese da superstição no prefácio do Tratado Teológico-Político de Espinosa
}

\author{
Eraldo Souza dos Santos*
}

\begin{abstract}
Resumo: 0 presente estudo busca estabelecer qual é o papel da insegurança humana na gênese dos comportamentos supersticiosos, assim como qual é a influência de tais comportamentos na vida política, com base na leitura do exordium do prefácio do Tratado Teológico-Político de Baruch de Espinosa. A proposta é realizar uma leitura estrutural desse texto, tendo como referência o ponto de vista dos afetos, isto é, da dinâmica afetiva dos seres humanos, para, assim, testar nossa hipótese, segundo a qual tal dinâmica e a superstição estão necessária e interiormente ligadas. A inconstância dos bens da fortuna e a insegurança que ela provoca, como será discutido no exordium, levam os homens aos comportamentos supersticiosos como estratégia afetiva para diminuir a angústia diante do mundo. Nesse ínterim, a gênese da superstição teria como causa o medo do que pode acontecer no presente e a esperança de que pode surgir no futuro algo melhor, duas faces distintas de um mesmo afeto. Tais práticas supersticiosas estariam presentes comumente na vida humana e não seriam necessariamente prejudiciais, mas surgem como problema, para Espinosa, a partir do momento em que são usadas por religiosos e governantes como estratégia para controlar os indivíduos e grupos participantes da vida política. Se o Estado nasce, como defenderá o filósofo, para diminuir a insegurança que se vive no estado de natureza, cumpre à vida política reduzir tal insegurança sem recorrer à manipulação dos afetos de parte de seus membros como forma de privilegiar determinado grupo.
\end{abstract}

Palavras-chave: superstição, afeto, flutuação do ânimo, fortuna.

Para Cléber, um solitário sem nome

\section{Exórdio}

Se os homens pudessem, em todas as circunstâncias,
decidir pelo seguro, ou se a fortuna se lhes mostrasse
sempre favorável, jamais seriam vitimas da supersti-
ção.

ESPINOSA, 2004, p. $111^{1}$

Se, neste estudo que começa agora a se desenrolar, iniciamos os trabalhos justamente como se inicia o Tratado Teológico-Político (TTP), é porque é ali, logo no começo do prefácio desse livro, que Espinosa levantará um argumento fundamental para traçar uma gênese para a superstição. Argumento que buscará dar

\footnotetext{
${ }^{*}$ Graduando em Filosofia - USP.

1 Doravante seguiremos essa tradução, embora por vezes sigamos também a tradução de André Rocha (2006), que revisa em sua dissertação de mestrado - Fortuna e superstição: um estudo desses temas no Tratado Teológico-Político de Espinosa - a tradução de Diogo Pires Aurélio. Nesse caso, indicaremos a alteração na nota de rodapé correspondente à citação.
} 
conta, numa mesma hipótese explicativa, tanto das pequenas crenças - como o receio de passar por baixo de uma escada ou o impulso para se esquivar de um gato preto - quanto da crença em um Deus transcendente, que levará à manipulação política de corpos políticos inteiros. Trata-se, desde o início, de apontar que é a insegurança ante a instabilidade da fortuna que leva o homem a ser supersticioso; insegurança que governa os afetos humanos diante de um mundo em que tudo parece ser regido pelo acaso, pela imprevisibilidade e pelos encontros fortuitos.

O prefácio prossegue e esclarece-nos melhor o que está em jogo nessa dificuldade em decidir pelo seguro diante de um mundo em que a fortuna nem sempre se mostra favorável.

\begin{abstract}
Mas, como se encontram frequentemente perante tais dificuldades que não sabem que decisão hão de tomar, e como os incertos bens da fortuna que desenfreadamente cobiçam os fazem oscilar, a maioria das vezes, entre a esperança e o medo, estão sempre prontos [os homens] a acreditar seja no que for: se tem dúvidas, deixam-se levar com a maior facilidade para aqui ou para ali; se hesitam, sobressaltados pela esperança e pelo medo em simultâneo, ainda é pior; porém se estão confiantes, ficam logo inchados de orgulho e presunção (ESPINOSA, 2004, p.111)2 .
\end{abstract}

Decerto se trata de um texto com muitas informações, que merecerão ser analisadas com cuidado e vagar. Mas há algo que merece ser apontado já neste momento inicial: os homens, ao se deixarem tomar por um desejo desenfreado pelos incertos bens da fortuna, oscilam entre a esperança e o medo, e, assim, deixam levar-se, "para aqui e para ali" - abrem espaço para serem manipulados. No fundo, o que parece estar na gênese da superstição, ao menos aqui no prefácio do TTP, é a insegurança humana diante da falta de constância do mundo. Insegurança que causa uma oscilação afetiva, tornando o homem vulnerável à manipulação. Parece que é justamente quando o homem se deixa oscilar, como oscilam as coisas do mundo e os bens da fortuna, justamente quando ele oscila, seguindo o movimento de oscilação do mundo, que ele se torna frágil e pronto para perder sua liberdade de ação, alienando-a. No fundo, o homem só pode se tornar supersticioso, nesse ínterim, porque ele precisa continuar vivo, porque ele quer perseverar na existência, porque ele precisa, de alguma maneira, suportar a insegurança do mundo. Contudo,

2 Com alteração: de "benefícios" da fortuna, por "bens da fortuna". 
essa parece ser uma faca de dois gumes, pois se diminui a insegurança ao custo da perda da liberdade.

Mas sigamos mais de perto o percurso do texto, para ver se tal hipótese se confirma. A proposta deste estudo é ler o texto com base no ponto de vista dos afetos, da dinâmica afetiva dos seres humanos, e buscar entender como essa dinâmica e a superstição estão necessária e interiormente ligadas. E buscar compreender também porque o método e o sistema espinosano exigem que, caso queiramos encontrar um remédio para a superstição, não será longe de onde ela nasce, mas ali onde ela teve sua gênese, na sua própria imanência.

Mas qual seria essa "imanência da superstição"? Se, como os comentadores que estão nas nossas referências bibliográficas ressaltam, a superstição pode ser afastada imanentemente por meio da emenda dos preconceitos, como dirá Espinosa lá no fim do apêndice da parte 1 da Ética, nossa hipótese aqui é precisa: o afastamento da superstição também passa necessariamente pelo controle da flutuação dos afetos. É justamente essa hipótese que guiará nossa leitura.

Em primeiro lugar, cumpre efetuar um recorte no caos, para tornar a dimensão do nosso trabalho viável. Seguiremos aqui a divisão de Fokke Akkerman, que mostra como o prefácio do TTP segue as recomendações dos retóricos, apresentando-se com base em uma já conhecida estrutura discursiva. 0 texto apresenta, segundo esse autor, cinco partes:

1. 0 exordium, que contém uma parte teórica sobre a superstitio. (Gebh. p. 5 a p. 7, linha 5);

2. A propositio, onde o tema do livro é deduzido da teoria precedente. (Gebh. p. 7, linha 6 a 35$)$;

3. A narratio, que expõe os fatos ou circunstâncias que levaram o autor a escrever o livro (Gebh. p.9 a p. 9, linha 15);

4. A divisio, quer dizer, um resumo e a subdivisão dos argumentos que servirão, nos 20 capítulos do livro, para provar a propositio. (Gebh. p. 9, linha 16 a p. 12, linha 2);

5. 0 epilogus ou a peroratio, em que o autor entra em contato direto com seu público. (Gebh, p.12, linha 2 ao fim) (Akkerman apud RocHA, 2006, p. 31).

O esforço de nosso estudo será justamente acompanhar a temática da insegurança no exordium do prefácio, para poder avaliar a hipótese que levantamos. Por isso, nossas análises se concentrarão fundamentalmente nesse texto, embora 
possamos recorrer a outros escritos de Espinosa e até mesmo a partes posteriores do TTP em determinados momentos.

A escolha pelo exordium, além de efetuar um recorte viável ao trabalho, também tem uma intenção relacionada intimamente ao objeto de estudo - pois será justamente nesse primeiro momento do livro que Espinosa apresentará, embora com aparente brevidade, a tese fundamental do seu livro. É em torno dessa "parte teórica", como a chama Akkerman, que os demais argumentos se alinharão.

\section{Delirantes}

Mas qual seria tal parte teórica fundamental para o livro e que nos é exposta no exordium? Qual é a teoria acerca da gênese da superstição que desde o início Espinosa nos apresenta? Aceitemos de início a resposta de Akkerman, que poderá nos servir de um bom guia. Apresentam-se no exordium, a seu ver, uma tese, qual seja, a de que "todos os homens são por natureza sujeitos à superstição", "as causas desta verdade (a tese é pois provada) e as consequências destas causas para a vida política e religiosa" (idem, ibidem).

Mas acompanhemos o movimento do texto para ver como as indicações de Akkerman podem ou não se confirmar. Sigamos rentes ao texto do exordium. Podemos continuar a ver como Espinosa apresenta ali, no início do prefácio, a maneira como a fortuna leva os homens à insegurança, e, assim, faz com que os seus ânimos se percam nos apetites imoderados pelos bens que ela pode proporcionar.

A fortuna carrega, justamente no modo como é representada pictoricamente, a imagem da possibilidade de uma alteração repentina de tudo o que parece constante no mundo. Ela é geralmente figurada, desde a Antiguidade, com uma roda, a roda do mundo, que está próxima à sua mão. Está sob o poder da fortuna girála, fazendo com que tudo se modifique, fazendo com que aquele que estava em cima, vá para baixo, e que aquele, que estava em baixo, vá para cima. Tudo com um só movimento e a seu bel-prazer: assim, a fortuna "vira o mundo de cabeças para o ar". De fato, parece que os "atos" da fortuna não envolvem qualquer previsibilidade. E a única previsibilidade que pode restar é a previsibilidade do imprevisível - no 
fundo, parece que só é possível saber que tudo poderá a qualquer momento se modificar e tomar outra forma.

Essa imagem da fortuna pode ajudar-nos a compreender ao que Espinosa se refere. Se não houvesse a fortuna e a sua roda, de fato, não haveria esperança, nem medo, pois é justamente tal movimento da fortuna, a insegurança inerente a ela, que faz os homens perderem o controle de seus próprios afetos. Diante das dificuldades que a fortuna proporciona aos homens, figura-se difícil para eles tomar qualquer decisão. Junto com a inconstância do mundo, com a inconstância dos bens da fortuna, os afetos tornam-se inconstantes. E, quando os homens estão nesse estado, deixam-se convencer seja pelo que for.

Mas se eles, por um lado, hesitam quando sobressaltados pelo medo e pela esperança, por outro, quando confiantes, incham-se de orgulho e presunção. Prosseguindo o argumento, Espinosa buscará mostrar a maneira como a inconstância do mundo gera a inconstância humana, dividindo o processo em dois ciclos: o ciclo em que a fortuna é favorável ao homem, levando-o a se jactar, a ser orgulhoso; e o ciclo em que ela o prejudica, levando-o ao medo, à insegurança.

Para mostrar como isso ocorre, o autor invoca uma percepção comum: "julgo que toda a gente sabe que é assim, não obstante eu estar convicto de que a maioria dos homens se ignora a si próprios" (ESPINOSA, 2004, p. 111). Não é preciso, de fato, ser filósofo, cientista ou profundo conhecedor da natureza humana para se aceitar a realidade dos fatos aos quais a descrição de Espinosa se refere; não, e mais uma das expressões do texto reforçam tal ideia: "não há, com efeito, ninguém que tenha vivido entre os homens que não tenha se dado conta de que..." (idem, ibidem).

E de quê? De que quando os homens estão em "uma maré de prosperidade", favorecidos pela fortuna, tendo acesso aos bens que ela proporciona, por mais ignorantes que sejam, julgam-se os mais sábios do mundo, de maneira que até a tentativa de lhes dar um conselho parece um insulto. Por outro lado, quando estão na adversidade, quando a fortuna não está a seu favor, viram-se para todas as direções, pedem conselhos de quem quer que seja, e seguem-nos, por mais "frívolos", "absurdos" e "inúteis" que sejam tais conselhos. O fundamental é que o processo ocorre de tal maneira que o ciclo se repete muitíssimas vezes. Sempre por "motivos 
insignificantes", os homens voltam a desejar melhores dias ou temer desgraças ainda piores. Oscilam entre a esperança pelo melhor e o medo pelo pior.

Abre-se aqui o campo para o surgimento da superstição. Amedrontado, o homem tende a interpretar como prenúncios de felicidade ou infelicidade os bens e os males pelos quais ele já passou. E mesmo que já tenha se enganado centenas de vezes acerca desses prenúncios, insiste em chamá-los de presságios, favoráveis ou funestos.

O insólito do mundo, para o supersticioso, é visto como prodígio, que revela "a cólera dos deuses ou do Númen sagrado" (idem, ibidem). Surge, assim, o caráter religioso da superstição. Torna-se um crime aos olhos de tais homens não aplacar a fúria de tais deuses pelas maneiras que estão às nossas mãos - mediante promessas e sacrifícios. "Submergidos na superstição", dirá Espinosa, tais homens "inventam mil e uma coisas e interpretam a natureza da maneira mais extravagante, como se ela toda delirasse ao mesmo tempo que [sic] eles" (idem, p. 111-12).

Mas qual é a causa desse delírio? Espinosa é claro a esse respeito: "quem nós vemos ser escravo de toda espécie de superstição são, sobretudo, os que desejam sem moderação os bens incertos" (idem, p. 112). Quando a fortuna não os favorece, imploram auxílio divino, "com lágrimas de mulher", e aceitam os devaneios de sua imaginação, os sonhos e as extravagâncias infantis como respostas divinas. Por outro lado, acusam a razão e chamam de inútil a sabedoria humana, pois, no seu delírio, a razão é cega e incapaz de indicar um caminho seguro. Um caminho seguro para obter as coisas vãs que desejam. A segurança será buscada lá nas extravagâncias, na imaginação, no sonho: nas entranhas dos animais, nos loucos, nos insensatos, nas aves, que revelam segredos, movidos pelo sopro divino.

O movimento do delírio não deixa de ser interessante: ele se duplica para fora do indivíduo, ele universaliza a experiência do delírio. Para que o delírio seja possível, é necessário que toda a realidade delire junto com o homem. É nessa duplicação que se revela o que de fato está por trás do caráter de credulidade ${ }^{3}$ que caracteriza o supersticioso. 0 crédulo, para que o mundo faça sentido, precisa jus-

\footnotetext{
3 Utilizamo-nos aqui de uma expressão utilizada por André Menezes Rocha (2008). Em sua análise, ele caracteriza o indivíduo supersticioso por duas propriedades: inconstância e credulidade. A inconstância será analisada mais à frente, quando nos dirigirmos especificamente para o campo dos afetos.
} 
tamente ter a crença de que Deus e Natureza desejam, oscilam, deliram como um ser humano deseja, oscila e delira. Operação tão necessária, quanto inconsciente.

Podemos dizer que o núcleo do delírio supersticioso é essa projeção de sua pessoa a tudo e a todos, projeção que é o antropomorfismo e personalização. 0 supersticioso crê, sem saber, talvez, que seus desejos imoderados por bens da fortuna, bem como suas vaidades e esperanças são o centro do universo, o núcleo em torno do qual gravita mesmo a vontade divina: o seu delírio é precisamente a construção de imagens acerca de uma natureza e de um deus girando em torno dos apetites humanos (RochA, 2008, p. 88).

Antropomorfismo e personalização - feitos à imagem e semelhança do homem, Deus e a Natureza deliram. 0 ânimo supersticioso é delirante justamente por ser produtor de imagens - produtor de uma imagem da natureza e de uma imagem do mundo, que criam um sistema no interior do qual a superstição é possível.

Mas isso só ocorre porque a imaginação, nesse momento, "dilata-se além de suas forças" (CHAUÍ, 2003, p. 100) . E, quando se dilata, a consequência é a produção de uma imagem deturpada do mundo, construída por gêneses inadequadas e cadeias causais criadas livremente pelo movimento imaginativo. Como lembra Chauí,

a imaginação (isto é, o conhecimento por meio de ideias imaginativas com que a mente interpreta as imagens produzidas em seu corpo pela ação das coisas externas) é um conhecimento abstrato porque é "uma conclusão sem premissas", pois é a tentativa para conhecer imediatamente a causa de um efeito sem percorrer a cadeia de mediações necessárias que o produzem, ou seja, é a construção de causas para explicar as coisas a partir dos estados do corpo afetado pelas imagens de outros corpos (idem, ibidem).

Além de inverter as causas pelos efeitos, a imaginação mantém efeitos cujas causas são ignoradas. Ela não consegue, dessa maneira, conhecer a causa geratriz dos objetos. Para Espinosa, de maneira semelhante ao adágio aristotélico, "conhecer é conhecer pela causa", é conhecer a ideia adequada do objeto, isto é, conhecer a causa eficiente interna necessária que é responsável pela essência ou pela natureza de determinado efeito. O fundamental aqui é que a imaginação, por não buscar as ideias adequadas das coisas, cria livremente um mundo; e que esse mundo é o mundo que sustenta a superstição.

\footnotetext{
${ }^{4}$ Chauí refere-se ao percurso do apêndice da parte 1 da Ética. Mas não parece incorreto dizer que, tanto lá como aqui no prefácio do TTP, é essa dilatação que torna possível a criação de uma imagem do universo da qual a superstição depende.
} 
Mas não podemos deixar de ter em vista que a construção desse mundo, como pudemos acompanhar, está a serviço de um projeto, embora possa falhar em diversos pontos na tentativa de realizá-lo: trata-se do projeto de alcançar a segurança. De fato, criar a imaginação, que oferece a imagem de deuses e de uma natureza caprichosos, é uma estratégia, inconsciente decerto, do homem para que ele próprio possa viver com uma maior segurança. Ora, mesmo que caprichoso e inconstante como o ser humano, esses deuses podem ser agradados e, em troca dos agrados, o homem pode receber os bens que cobiça e a segurança que no fundo deseja. Talvez Deus seja menos inconstante do que a fortuna, e essa seja uma boa aposta... Se, como lembra Rocha (2006), a grande criação do ânimo supersticioso é, precisamente, "um deus que compactuaria com os supersticiosos e que concederia bens da fortuna em troca de bajulações e rituais de glorificação" (p. 90), no fundo, é porque tal deus acalma o ânimo humano, ajuda-o a perseverar na existência. Pois só é possível a vida humana com alguma segurança, alguma alegria.

Mas essa ainda não é uma solução viável para o problema da insegurança. E por quê? Porque ainda assim o homem continua preso aos bens da fortuna, à oscilação, de maneira que a segurança é provisória e os ciclos da fortuna sempre recomeçam. Porque ainda assim ele está vulnerável à manipulação.

\section{Amedrontados}

Mas se conhecer é conhecer pela causa, pela causa geratriz, qual é a causa da superstição? A causa da superstição é o medo. "O medo é a causa que origina, conserva e alimenta a superstição" (idem, ibidem).

Para aqueles que ainda não estão completamente convencidos disso, Espinosa recorrerá a exemplos. Reportando-se a Cúrcio, historiador antigo que escreveu acerca da superstição em História de Alexandre, o Grande, nosso autor lança mão de exemplos relacionados à vida do próprio Alexandre para convencer os mais céticos quanto aos seus argumentos.

Se depois, do que já dissemos, alguém quiser ainda exemplos, veja-se Alexandre, que só se tornou supersticioso e recorreu aos adivinhos quando, às portas de Susa, começou a temer pela sua sorte (vide Q. Cúrcio, Livro V, §7); assim que venceu Dario, desistiu logo de consultar os adivinhos e arúspices. Até ao momento em que, uma vez mais aterrado pela adversidade, abandonado pelos Bactrianos, atacado pelos Citas e imobi- 
lizado devido a uma ferida, recaiu (como diz o mesmo Q. Cúrcio, Livro VII, §7) na superstição, esse logro das mentes humanas, e mandou Aristrando, em que depositava uma confiança cega, explorar por meio de sacrifícios a evolução futura dos acontecimentos (ESPINOSA, 2004, p. 112).

Aqui podemos notar novamente aqueles dois ciclos do ânimo humano diante da má e da boa fortuna. Mas algo se acrescenta com esse exemplo, pois parece que é justamente quando está abatido pelos infortúnios, pelo medo diante da fortuna, que o indivíduo se deixa dominar pela superstição. 0 que leva, pois, Alexandre a esse "logro das mentes humanas"?

Quando começa a temer pela sua sorte, Alexandre recorre aos adivinhos, para saber se os deuses estão ou não a seu favor. Ciclo do medo, da necessidade dos conselhos. Quando, por outro lado, vence Dario, desiste de consultá-los. É o ciclo da soberba, do orgulho, como vimos, no qual todo conselho parece inútil. Mas a fortuna prossegue com sua inconstância - "até o momento em que, uma vez mais aterrado pela adversidade...". O medo retorna, Alexandre deixa tomar-se por ele, o ciclo recomeça. 0 exemplo, assim, reforça a tese pela qual "os homens só se deixam dominar pela superstição enquanto têm medo" (idem, ibidem). De fato, Alexandre só se deixou tomar pela crença nos presságios e nos adivinhos em seus momentos de infortúnio, quando, apoderado pelo medo, viu-se propenso a buscar ajuda em todas as partes. Somente nesse momento, seu ânimo, amedrontado e triste, foi tomado por fantasmas e delírios supersticiosos.

O próximo passo do argumento espinosano é fundamental e inovador, muito embora venha - artifício retórico - sob a etiqueta do já sabido. Quase de passagem, Espinosa diz que "mas como tudo isto, ao que presumo, é suficientemente conhecido de todos, não insistirei mais no assunto" (idem, ibidem) ${ }^{5}$. 0 suficientemente conhecido por todos, aqui, é a parte propriamente política da teoria da superstição de Espinosa. Pois, dirá o autor, é justamente quando os Estados se encontram em maiores dificuldades que os adivinhos detêm sobre a plebe o maior poder; mas não só sobre elas como também sobre os próprios reis. Pois é justamente nesses momentos de infortúnio e de dificuldade que o medo dos cidadãos cresce, de forma que os

\footnotetext{
5 Não só essa parte do argumento como as anteriores relativas ao exemplo de Alexandre entram nessa categoria do "suficientemente conhecido".
} 
adivinhos surgem como intermediários entre os deuses e os homens; intermediários capazes de inverter a fortuna da cidade. É assim que Espinosa passa do exemplo do indivíduo para o Estado, mostrando como a superstição individual toma conta da coletividade de indivíduos que vivem uma vida comum.

\section{Apaixonados}

Mas deixemos ao menos por um momento essa questão fundamental de lado e prossigamos ao menos por um tempo no indivíduo tomado em sua singularidade. Pois Espinosa, a essa altura, começará a extrair do seu argumento as consequências que deseja - se é natural ao homem ter medo e o medo é a causa da superstição, então todos os homens estão naturalmente sujeitos à superstição. Tal era, como vimos, a "tese fundamental" que Akkerman dizia estar presente no exordium. É, assim, da natureza humana a propensão à superstição. É, mais propriamente, da natureza dos seus afetos, da inconstância, da multiplicidade e da variabilidade dos afetos humanos que a superstição pode surgir:

Que ela [a superstição] deve ser extremamente variável e inconstante, como todas as ilusões da mente e os acessos de furor, e por último, que só a esperança, o ódio, a cólera e a fraude podem fazer com que subsista, pois não provém da razão, mas unicamente da paixão, e da paixão mais eficiente (ESPINOSA, 2004, p. 112-13).

A superstição está, dessa maneira, relacionada à paixão e à paixão mais eficiente. Vem daí a sua força. Ela toma conta dos afetos humanos pelo medo, diminuindo a potência do homem. Mas o que isso pode significar? Fazer um pequeno incurso na teoria espinosana do conatus, neste momento, pode esclarecer-nos o que está em jogo nessa "flutuação afetiva".

Para Espinosa, todos os indivíduos singulares são conatus, ou seja, "uma força interna que unifica todas as suas operações e ações para permanecer na existência” (CHAUÍ, 2006, p. 102). O conatus, como demonstra o autor na parte III da Ética, é a essência atual do corpo e da mente. Em primeiro lugar, isso significa dizer que o ser humano não é realização particular de uma essência universal, mas uma singularidade individual, portadora de sua própria essência. Significa também, em segundo lugar, que ele não é uma inclinação virtual, mas que está sempre em ação. 
Além disso, e fundamentalmente, as operações que o indivíduo empreende para permanecer na existência são logicamente anteriores à sua distinção como boas ou más, certas ou erradas. E sendo o conatus sempre em ato, essa tendência não busca uma finalidade de realização - as ações são causas eficientes determinadas por causas eficientes, e não por fins.

É do conatus que decorre a essência do homem: "O desejo (cupiditas) é a própria essência do homem enquanto concebida como determinada a fazer algo, em virtude de uma afecção qualquer nela encontrada" (Espinosa apud CHAUÍ, 2006, p. 102). A tendência do conatus é sempre passar para uma perfeição maior, para uma potência maior - quer dizer, para uma alegria. Ele tende a buscar afetos alegres, que o mantenham na existência. Mas sempre existirão encontros fortuitos, a fortuna, de forma que ele poderá sempre perder potência, passar para um estado de tristeza, de perfeição menor.

Ora, se desejar é da essência do homem, se os afetos, propriamente falando, são-lhes algo inerente, podemos compreender melhor agora porque a superstição é natural. Podemos, ainda mais, compreender agora como a superstição no fundo é uma estratégia humana para perseverar na existência, ponto pelo qual passamos de maneira um tanto veloz. Espinosa conceberá a existência de afetos que fazem o conatus aumentar ou não sua perfeição, aumentar sua alegria ou a sua tristeza. 0 medo, o afeto que mais estreitamente está ligado ao ânimo supersticioso, é um afeto triste. De fato, "o medo (Metus) é uma tristeza instável nascida da ideia de uma coisa futura ou passada, do resultado da qual duvidamos numa certa medida" (EsPINOSA, 1983, p. 214).

Mas mesmo sendo uma tristeza, o medo não está separado do afeto alegre, que é seu oposto, a esperança. No fundo, esses dois afetos são inseparáveis, pois

não há esperança sem medo. Aquele, com efeito, que está em suspenso pela esperança e duvida do resultado de uma coisa, supõe-se imaginar qualquer coisa que exclui a existência da coisa futura, e, por conseguinte, nessa medida, supõe-se que se entristece (pela proposição 19 desta parte); e, consequentemente, enquanto está suspenso pela esperança, tem medo de que a coisa não aconteça. Aquele que, ao contrário, é vítima do medo, isto é, duvida do resultado de uma coisa que odeia, imagina também qualquer coisa que exclui a existência dessa coisa; e, por conseguinte (pela proposição 20 dessa parte), alegra-se, e, consequentemente, nessa medida, tem esperança de que essa coisa não acontecerá (idem, ibidem). 
Essa oscilação entre medo e esperança poderia ser vista somente como um problema. Afinal de contas, como estamos vendo, a oscilação é que faz o homem cair na superstição. Mas no fundo, o que o homem busca é perseverar na existência e perseverar na existência significa perseverar na alegria. A superstição, de alguma maneira, busca dar ordem ao caos, instaurar uma segurança, aumentar a esperança por algo melhor. E, nesse sentido, a superstição e o medo ajudam o ser humano a perseverar na existência, de maneira que há neles algo de positivo.

Todavia, como vimos, a superstição ainda é inconstante, pois oscila com a fortuna e com os seus bens. Seria necessário, assim, encontrar uma saída para a superstição. Pois ela está ligada a objetos que fazem o ser humano entrar numa falsa estabilidade - basta um dos novos ciclos da fortuna, para todo o sofrimento humano continuar. Também, porque ela torna o ser humano propenso a ser manipulado. Com os afetos em estado de inconstância, os seres humanos se entregam à toda sorte de superstição; e não faltam sacerdotes e adivinhos para motivá-los a essas crenças e, por meio delas, poder manipulá-los.

Mas o que pode significar "encontrar uma saída" nesse caso? Não pode significar lançar mão do ser humano que de fato existe, pois sabemos que a superstição é natural ao homem, de forma que ignorar isso seria chegar a uma falsa solução.

Os filósofos concebem as emoções que se combatem entre si, em nós, como vícios em que os homens caem por erro próprio; é por isso que se habituaram a ridicularizá-los, deplorá-los, reprová-los ou, quando querem parecer mais morais, detestá-los. Julgam assim agir divinamente e elevar-se ao pedestal da sabedoria, prodigalizando toda a espécie de louvores a uma natureza humana que em parte alguma existe, e atacando através de [sic] seus discursos a que realmente existe. Concebem os homens, efetivamente, não tais como são, mas como eles próprios gostariam que fossem. Daí, por consequência, que quase todos, em vez de uma ética, hajam escrito uma sátira, e não tinham sobre política vistas que possam ser postas em prática, devendo a política, tal como a concebem, ser tomada por quimera, ou como respeitando ao domínio da utopia ou da idade do ouro, isto é, a um tempo em que nenhuma instituição era necessária. Portanto, entre todas as ciências que têm uma aplicação, é a política o campo em que a teoria passa por diferir mais da prática, e não há homens que se pense menos próprios para governar o Estado do que os teóricos, quer dizer, os filósofos (EsPINOSA, 1983, p. 439).

Ignorar os afetos significa ignorar o ser humano. Qualquer projeto de política que tente fazê-lo pertence ao reino da quimera, da utopia. Mas se não é possível buscar a solução por meio de um ser humano ideal, sem afetos ou ao menos sob 
pleno domínio deles, já que um ser humano dessa natureza não existe, qual seria, então, a saída?

Decerto trata-se de uma resposta muito complexa, que ultrapassa os limites do nosso estudo, mesmo porque ultrapassa os limites do exordium. Mas o texto que analisamos sugere por si uma resposta. Durante todo o percurso pudemos perceber como sempre a superstição esteve associada ao instável, ao variável, ao inconstante, à oscilação, à dúvida, à incerteza. Uma breve leitura do exordium possibilita verificar como as palavras desse campo semântico são recorrentes no texto. A experiência do medo é justamente a experiência da insegurança, do medo diante da fortuna, que dá e retira os objetos do desejo. Talvez um caminho para achar "uma saída", para evitarmos a superstição, seja buscar a segurança como alternativa para nos desvencilharmos do medo que nos amedronta e que nos entristece. Isso significa criar maneiras de conter a flutuação dos afetos.

\section{Considerações finais}

No idioma dos primórdios da filosofia europeia, a comunicação do medo era chamada de superstição. E de fato a política do medo sempre foi espalhada por uma espécie de superstição.

HARDT; NEGRI, 2005, p. 344

Há diversos modos de abordar, na obra espinosana, o afastamento da superstição e a busca por bens seguros. Por exemplo, no apêndice da parte 1 da Ética, Espinosa falará da "emenda dos preconceitos". Também na Ética, do amor intelectualis, do sumo bem. A busca do bem verdadeiro também será tema do Tratado da emenda do intelecto. Em nossa conclusão, a temática será centrada na análise do exordium, que o trabalho empreendeu.

O original nesse texto de Espinosa é que ele traça uma teoria política que leva em conta justamente como o sistema de desejos do indivíduo pode ser mobilizado na e para a vida política. De fato, "se não há nada mais eficaz do que a superstição para governar as multidões", é porque a superstição está intrinsicamente ligada à dinâmica dos afetos, ao medo e à soberba dos indivíduos, que o sacerdote e o adivinho sabem bem manipular. A vida política nasce justamente de uma neces- 
sidade afetiva do indivíduo ${ }^{6}$. 0 Tratado Político, por exemplo, mostrará esse percurso, pelo qual o homem, inseguro e amedrontado no estado natural, entra no estado civil, no qual troca o incerto pelo seguro.

Mas que não nos enganemos: a vida política não é só segurança. 0 projeto do TTP é justamente mostrar como ocorre a manipulação dos afetos por aqueles ligados ao poder teológico-político. E não pode ser separado - mesmo quando imergimos, como neste trabalho, na leitura estrutural do texto - da defesa, que Espinosa empreende, do governo dos De Witt numa Holanda dividida por conflitos políticos entre a monarquia e a república, da oposição do filósofo ao partido orangista, e da revolta de nosso autor diante da pena de morte de um dos seus melhores amigos, Adrian Koerbagh, por opor-se às ideias religiosas estabelecidas.

A promessa, que aqui é acusada como perigosa, é de uma falsa segurança, pois não é possível estar seguro enquanto se está sendo manipulado. Só podemos estar seguros quando somos livres. É justamente por causa da manipulação que esses adivinhos e sacerdotes podem desejar que o homem permaneça no medo, que oscile como oscila a fortuna, que seja inconstante como os bens incertos que desejam.

Mas para sair desses círculos viciosos é necessária a filosofia; mais precisamente, a liberdade de filosofar, que o título do $\mathrm{TTP}^{7}$ relaciona estreitamente à possibilidade da paz e da piedade em um Estado. É necessário que o homem se utilize da razão e que controle a flutuação inconstante de seus afetos. Pois, por mais que o homem seja naturalmente propenso à superstição, ainda restam qualidades também naturais das quais ele pode se servir para evitar cair a todo momento no medo. A razão cumpre aqui esse papel.

\footnotetext{
6 Trata-se de uma ideia acerca do político que está presente também em muitos outros autores. Em Adorno e Horkheimer, por exemplo, discutir-se-á como no fundo o nazismo funciona como regime político porque consegue dar conta da economia libidinal do povo. Aqui, embora economia libidinal possa parecer um termo anacrônico, é exatamente do que se trata: os adivinhos e os chefes religiosos podem e sabem manipular os afetos humanos.

7 O título completo do TTP é: Tratado Teológico-Político contendo algumas dissertações em que se demonstra que a liberdade de filosofar não só é compatível com a preservação da piedade e da paz como, inclusivamente, não pode ser abolida sem se abolir ao mesmo tempo a paz do Estado e a própria piedade (ESPINOSA, 2004, p. 105). Sem liberdade de pensamento, portanto, não há paz, e, se não há paz no Estado, não há propriamente vida política.
} 
Mas aqueles homens que desejam que as coisas permaneçam como estão, obviamente não podem aceitar esse fato:

foi, de resto, para prevenir esse perigo que houve sempre o cuidado de rodear a religião, fosse ela verdadeira ou falsa, de culto e aparato, de modo a que [sic] se revestisse da maior gravidade e fosse escrupulosamente observada por todos. Entre os turcos, isso foi tão bem sucedido que até o simples discutir eles consideram crime, deixando a inteligência ocupada com tantos preconceitos que não há mais lugar na mente para a reta razão, nem sequer para se duvidar (ESPINOSA, 2004, p. 113).

Os homens naturalmente desejam, naturalmente têm afetos, naturalmente têm medo, naturalmente querem perseverar na existência. Para manipular os homens é necessário justamente manipular seu medo, manipulá-los em sua fraqueza. Mas há uma saída: pois ainda há espaço para a reta razão, para a "emenda dos preconceitos" e, no caso da vida política, para o que Rocha (2006) chama de "emenda das instituições". Isso significa retrabalhar o próprio desvio e a própria dificuldade no interior de sua própria imanência, pensar a solução do problema tomando como base a sua própria constituição. É quando "emendamos" o medo, a esperança e os preconceitos, isto é, quando trabalhamos suas potências positivas, que são inerentes a ele, que podemos ser senhores do medo, manipulá-lo. 0 jogo se inverte. Há algo de bom na esperança - ela nos auxilia, por mais que também possa levar-nos ao erro e ao falso, a prosseguir vivos.

Ainda há, assim, espaço para a alegria na vida política, para que se busque lutar contra esses "fantasmas e delírios dos ânimos tristes e amedrontados". Ainda há espaço para busca da verdadeira segurança. Toda a vida política começa para afastar o medo e, por essa razão, afastar o medo quando ele se imiscui na vida política novamente é uma das maiores tarefas, a qual podemos nos dedicar para que o homem persevere na existência.

\section{Referências}

Chauí, M. (1995). Espinosa: uma filosofia da liberdade. São Paulo, Moderna. . (2003). “Direito é potência: experiência e geometria no 'Tratado Político'”. In: . Política em Espinosa. São Paulo, Companhia das Letras.

. (2004). "O retorno do teológico-político". In: CARDoso, S. (org.). Retorno ao republicanismo. Belo Horizonte, UFMG. 
. (2006). "Espinosa: poder e liberdade". In: Boron, A. Filosofia política moderna. De Hobbes a Marx. São Paulo, DCP-FFLCH. Disponível em: $<$ http:// bibliotecavirtual.clacso.org.ar/ar/libros/secret/filopolmpt/filopolmpt.pdf $>$. Acesso em: 14 jun. 2011.

EsPinosa, B. (1983). Pensamentos metafísicos; Tratado da correção do intelecto; Ética; Tratado político; Correspondência. São Paulo, Abril Cultural.

(2004). Tratado Teológico-Político. Tradução, introdução e notas de Diogo Pires Aurélio. Estudos Gerais, Série Universitária, Clássicos de Filosofia. Lisboa, Imprensa Nacional - Casa da Moeda.

HARDT, M.; NEGRI, A. (2005). Império. Rio de Janeiro, Record.

Rocha, A. M. (2006). Fortuna e superstição: um estudo desses temas no Tratado Teológico-Político de Espinosa. 111f. Dissertação (Mestrado em Filosofia) - Faculdade de Filosofia, Letras e Ciências Humanas, Universidade de São Paulo, São Paulo.

. (2008). "Espinosa e o conceito de superstição". Cadernos de Ética e Filosofia Política 12, p. 81-99.

SAnTiago, H. (2009). "Superstição e ordem moral do mundo". In: MarTins, A. (org.). O mais potente dos afetos: Spinoza e Nietzsche. São Paulo, Martins Fontes.

Recebido em setembro/2011

Aprovado em dezembro/2011 